\title{
Elections to the PEC of the BDA
}

Nominations are sought for the following seats on the Principal Executive

Committee (PEC):

\section{England:}

- Eastern (one seat)

- North West (one seat)

- West Midlands (one seat)

- Wales (one seat)

- UK-wide (two seats).

The two UK-wide seats include one scheduled election and one by-election, the term of which will run until December 2022.

The PEC has overall responsibility for the control and direction of the policy and affairs of the British Dental Association (BDA) and its members are the directors of the Association.

There are 15 members on the PEC. Each will have a share of overall responsibilities, and typically this will require:
- Attendance at all meetings of the PEC around five a year, but maybe more when business demands

- Attendance at own country council meetings - usually three a year

- Attendance at UK Council meetings around two a year

- Sit on 1-2 sub committees/issue specific forums

- Attend general meetings of the Association.

It is anticipated that the approximate time commitment for a member of the PEC will be 20 days per year, with an annual remuneration of $£ 15,000$.

\section{Term of office}

This shall be until December 2023 (or 2022 for one of the UK-wide seats), with the opportunity to stand for a further full threeyear term of office at that point.

\section{Induction, support and training}

Membership of the PEC carries significant organisational and legal responsibilities. There is an induction programme for those elected, and ongoing training. Members will also have advice and support from the Chief Executive and the wider BDA Team.

\section{Next meetings of the PEC}

Meetings of the PEC in 2021 are currently scheduled for: Wednesday $3 \& 4$ February, Thursday 6 May, Wednesday 7 July, Wednesday 8 September and Wednesday 1 December.

Nomination forms must be submitted online by 17.00 Friday 2 October 2020. A link to the online nomination portal can be found at www.bda.org/elections.

For more information about the elections to the PEC or the role of a PEC member please contact the BDA's Election Manager Stephen Skelton on 0207563 4141 or email stephen.skelton@bda.org. 